\title{
Virtual inertia with PV inverters using DC-link capacitors
}

\author{
Eberhard Waffenschmidt \\ CIRE - Cologne Institute for Renewable \\ Energy at TH-Köln \\ Betzdorferstr. 2 \\ 50679 Köln, Germany \\ +4924182752020 \\ eberhard.waffenschmidt@th-koeln.de \\ https://www.fh-koeln.de/ \\ personen/eberhard.waffenschmidt/
}

\author{
Ron S.Y. Hui \\ The University of Hong Kong, \\ Department of Electrical \& Electronic \\ Engineering \\ Pokfulam Road, \\ Hong Kong \\ ronhui@eee.hku.hk
}

\section{Acknowledgments}

The following persons contributed to this publication with parts of their student works: Daniel Wagner, Markus Korbmacher, Bente Muhr, Sonny Glesmann and Nora Kovacs

\section{Keywords}

«Control methods for electrical systems», «Distribution of electrical energy», «Photovoltaic», «Renewable energy systems», «Smart grids», «Smart microgrids», «Transmission of electrical energy»

\begin{abstract}
Soon, virtual inertia for grid control must be covered by photovoltaic inverters. It is suggested to use DC link capacitors for this task. This requires $5 \mathrm{~W}, 50 \mathrm{~J}$ and a capacitor size of about $200 \mathrm{~cm}^{3}$ per installed $\mathrm{kW}$, corresponding to the size of single phase DC link capacitors. It is shown that the additional power ripple (and thus current ripple) is in the order of $0.1 \%$ and the voltage ripple of the intermediate voltage will typically remain between $+/-3.6 \%$. The related control can be easily extended by adding a voltage signal to the control voltage, which is proportional to the frequency deviation. Then, the existing controller inherently sets the required additional power fluctuation required for the virtual inertia function.
\end{abstract}

\section{Introduction}

Renewable energy sources put new burdens on the electrical power grid. While fluctuating generation can be compensated by storages [1] [2], the grid control also faces challenges: At certain times, renewable energy sources contribute already up to $85 \%$ to the power consumption in Germany (see Fig. 1, based on data from [3]), and soon shares of $100 \%$ for longer periods are expected [4].

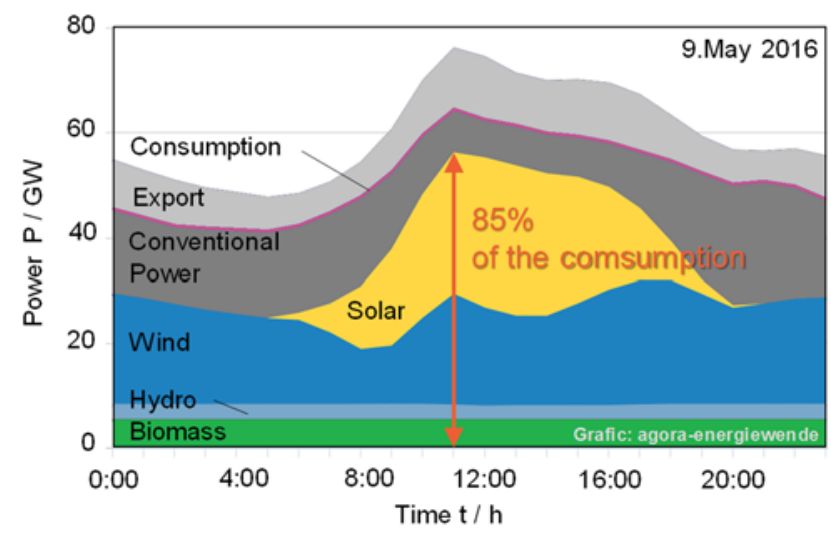

Fig. 1: Power generation and demand in Germany in May 2016, graphic based on [3]. 
Most of this power is generated by electronic power converters without rotating inertia. Fortunately, Germany's grid is part of the ENTSO-E, European Network of Transmission System Operators for Electricity, and today the missing inertia can be compensated by the other members, which have less renewable energies [5]. However, in future, also their inertia may vanish leading to larger frequency deviations as illustrated in Fig. 2.

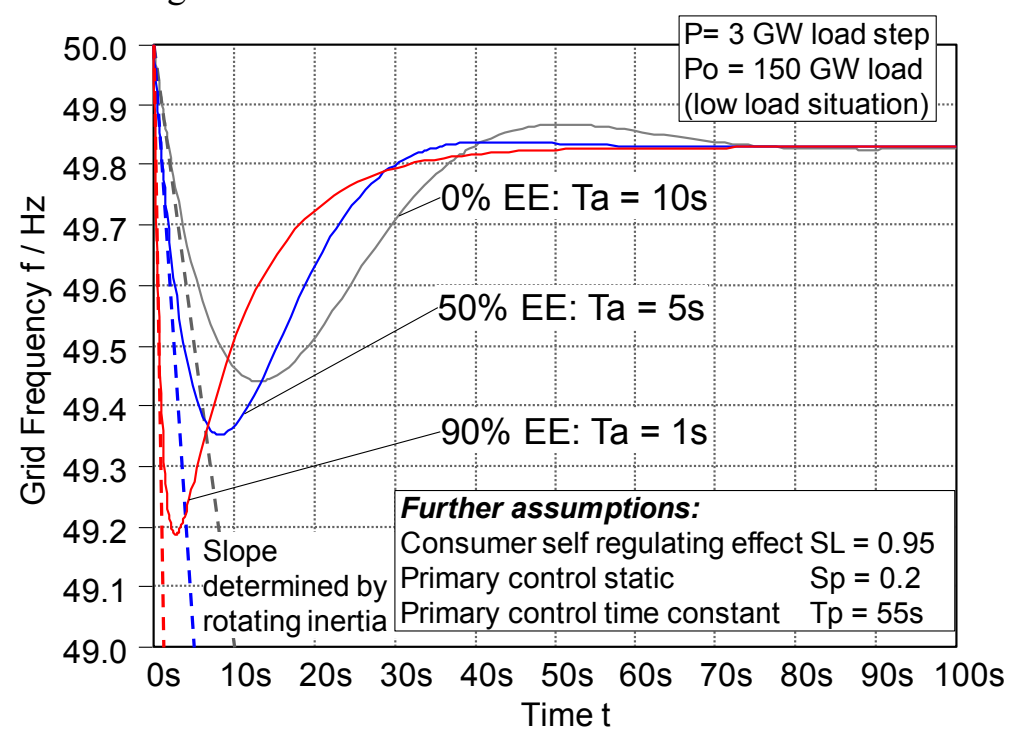

Fig. 2: Frequency reaction on a $3 \mathrm{GW}$ load step in the European grid with different amounts of inertias.

This figure is a simulation of the reaction of the grid frequency $f$ (related to the nominal frequency $f_{0}$ ) to a load step of $P=3 \mathrm{GW}$ in the European grid at low load situation with $P_{0}=150 \mathrm{GW}$ load. It includes instantaneous reaction, primary control and the consumer self-regulating effect. Approach and used values (see figure) are taken from [6] leading to the equation use for the simulation:

$$
f / f_{0}=\left[\frac{1}{j \omega T_{A}}\left\|S_{L}\right\|\left(S_{P}+j \omega S_{P} T_{P}\right)\right] P / P_{0}
$$

where $\omega$ is the system reaction angular frequency. With less available inertia the time constant $T_{a}$ will be smaller leading to a faster decay of the frequency in case of a load loss event. It shows that it is necessary to provide virtual inertia in order to limit the frequency drop in such a case.

Then this instantaneous reaction on load steps must be covered by the feed-in inverters [7] [8] [9], in the worst case by one of the contributors like photovoltaic (PV). To provide instantaneous reaction control, [5] mentions the following solutions: batteries combined with PV systems or curbing the generation in order to have a margin for positive control power. Both solutions are costly. Another possibility is using the inertia of wind rotors, like offered by several wind generator manufactures and which is required in Quebec's (Canda) according to its grid code [10]. However, any change of the rotating inertia leads to a deviation from the maximum power point of the wind turbine, and a certain time is necessary for the wind turbine to recover from the deviation [11]. This leads to some financial losses. Finally, modifying no longer used rotating generators as control power devices are possible. However, these solutions are either costly or not sufficient. In its latest grid code ENTSO-E requires synthetic inertia for type $\mathrm{C}$ power park modules of more than one MW in the case of a low frequency event, but not during normal operation (article 16.2 and 49.5 [12]).

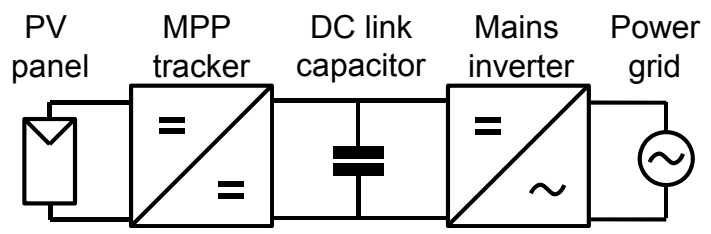

Fig. 3: Considered topology. 
Here, here a solution for PV inverters is investigated, which provides instantaneous reaction control with minimized effort and no curbing and which is possible also for small inverters. For this purpose, the energy storage of intermediate voltage electrolytic capacitors (elcaps) is proposed. Fig. 3 shows the considered topology, which is nothing special related to its hardware.

\section{Power and energy requirements}

In a first step, the requirements for the worst case in the European ENTSO-E grid and the consequences for the power and energy requirements of the instantaneous reaction are derived. It is assumed that only the instantaneous reaction similar to the inertia of rotating generator masses is considered, while the following primary control is taken over by dedicated sources in the grid. Then, the photovoltaic system can recover after an event, to always operate at maximum power. To get the power and energy requirements, the methodology and data of reference [5] is used (see Fig. 4): a worst case event of a sudden lack of $3 \mathrm{GW}$ power in the ENTSO-E grid is assumed. This requires $372 \mathrm{MW}$ in the German grid. Assuming the primary control taking over with a linear increase within $20 \mathrm{~s}$ [5], this requires energy of $3720 \mathrm{MJ}$. This power and energy is related to a future assumed installed power of PV systems. As a rough estimation, it is assumed that in a worst case only PV provides the peak demand of $80 \mathrm{GW}$ and thus the installed power of the PV systems is assumed as at least $80 \mathrm{GW}$ (in fact, to supply $80 \mathrm{GW}$ reliably demands much more installed power, but this would make the estimations less severe for the individual inverter). Taking this $80 \mathrm{GW}$ as a reference leads to $4.6 \mathrm{~W} / \mathrm{kW}$, rounded up to $5 \mathrm{~W} / \mathrm{kW}$. Concluding, additional power of $5 \mathrm{~W}$ and energy of $50 \mathrm{~J}$ per installed $\mathrm{kW}$ power capacity is needed to cover one worst case event. It should be noted that these numbers refer to the installed power of PV systems, not to the power they actually feed in. Thus, the power of one inverter needed for the virtual inertia is related to the rated power and not to the power it actually provides.

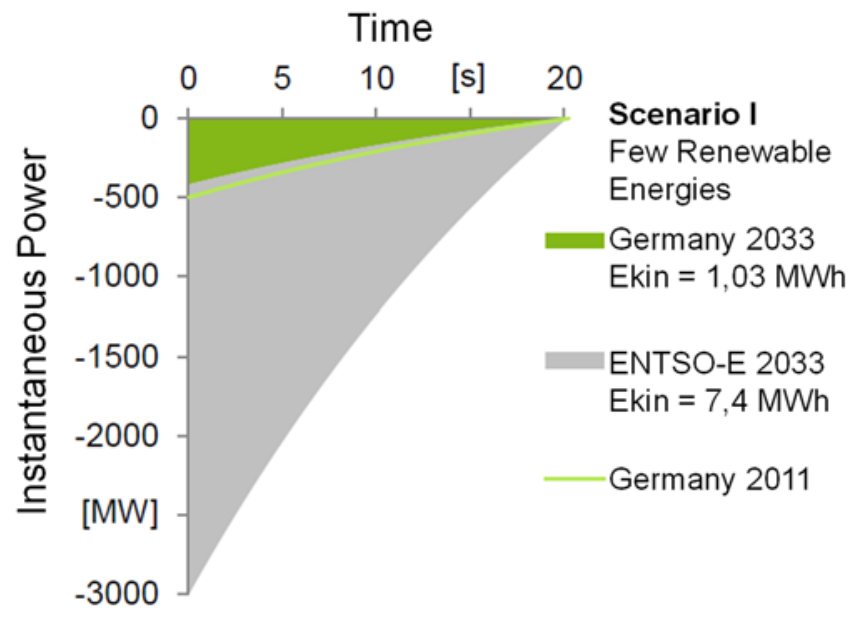

Fig. 4: Power requirements for a worst case load step of $3 \mathrm{GW}$ in the European ENTSO-E grid [3].

This level of power can easily be processed by the main inverter. The amount of energy relates to the energy content of a somewhat larger DC link capacitor (details see following chapter). Therefore, it is suggested to store the required energy in a capacitor linked to the intermediate DC voltage.

\section{Needed capacitor size}

Typically, the size of a capacitor relates to its maximum energy content. To determine the interdependence, the capacity, rated voltage, diameter and height of more than 200 electrolytic capacitors are collected from the website of an electronic components distributor [13]. Rated energy and volume are calculated from this data and shown in Fig. 5. In real circuits, not the maximum rated energy capability $E_{\max }$ can be used, because the capacitor is discharged from the maximum voltage $U_{\max }$ only by a voltage difference $\Delta U$. Then the usable energy $E_{\text {use }}$ is:

$$
E_{\text {use }}=E_{\max } \cdot\left[1-\left(1-\Delta U / U_{\max }\right)^{2}\right]
$$


This equation is used to illustrate in Fig. 6 (orange trace), which $E_{\max }$ is necessary, if the required energy of $50 \mathrm{~J}$ is stored. The blue curve relates to the volume using the fit function in Fig. 5.

The maximum voltage has no influence on the needed energy content of the capacitor and thus low influence on the capacitor size. The voltage can thus be freely selected from a capacitor point of view. Only the relative voltage difference, which can be considered as relative voltage ripple, determines the size. However, restrictions of the application have to be kept in mind: the grid inverter needs a minimum voltage to work correctly when directly connected to the grid (without a transformer) and the grid inverter cannot support too high voltage (due to semiconductors limits).

Using the DC link capacitor the ripple should remain below $10 \%$. To have $50 \mathrm{~J}$ available, this requires at least a rated energy content of $300 \mathrm{~J}$, resulting in a capacitor volume of about $200 \mathrm{~cm}^{3}$ (e.g. $10 \mathrm{~cm}$ height, $5 \mathrm{~cm}$ diameter) to $400 \mathrm{~cm}^{3}$. Such a size could reasonably relate to a somewhat larger intermediate voltage capacitor of a $1 \mathrm{k} \mathrm{W}$ a single phase inverter.

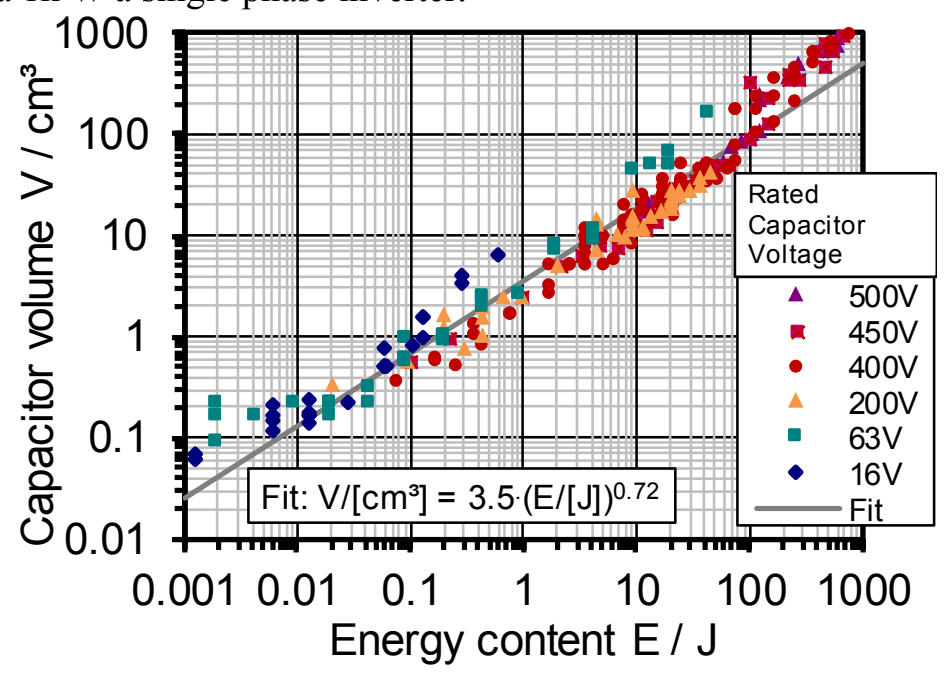

Fig. 5: Volume size of electrolytic capacitors. Various electrolytic capacitors, data from [13].

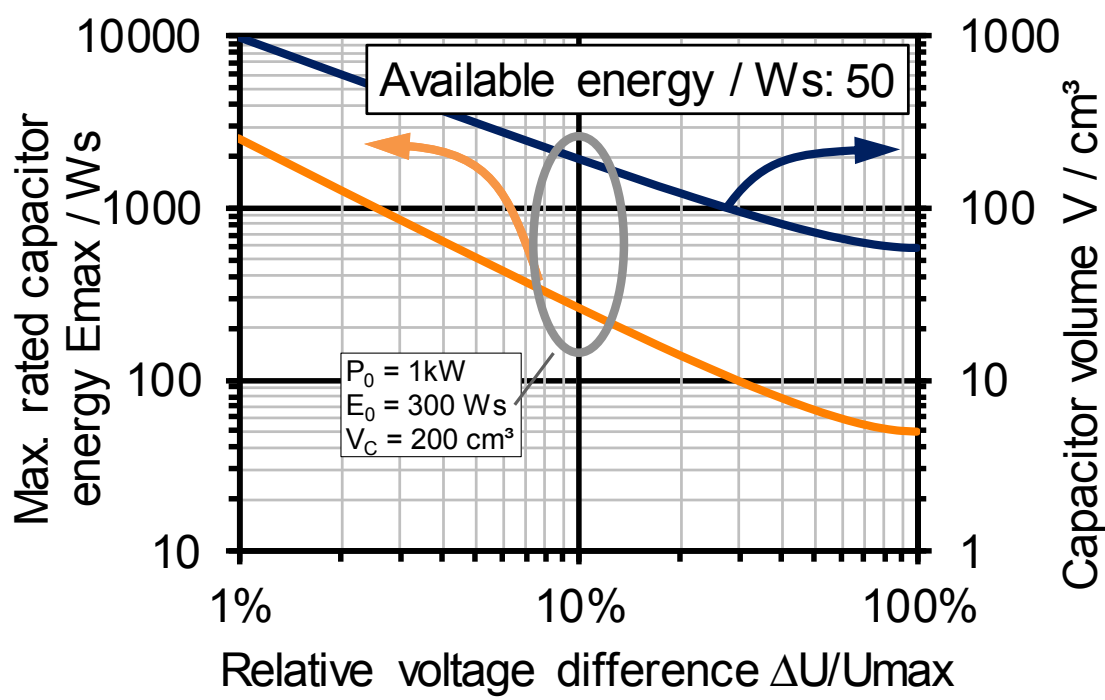

Fig. 6: Needed capacitor energy and volume size to store $50 \mathrm{~J}$.

\section{Power and voltage fluctuations}

During daily operation, much smaller deviations from the desired operation point are expected than in a worst case. Therefore, this chapter shows the effect on the related components during daily operation, which gives an indication on their stress, rather than the worst case, which very seldom happens. 
In a rotating generator, for small changes of power the rotational speed decreases while delivering a constant excess of power. Therefore, applying a virtual inertia, the required control power $\Delta P$ must be dependent on the time derivative of the frequency deviation $\Delta f$ from the nominal frequency $f_{0}(50 \mathrm{~Hz})$ :

$$
\frac{\Delta P(t)}{P_{0}}=T_{a} \cdot \frac{d}{d t} \frac{\Delta f(t)}{f_{0}}
$$

$P_{0}$ is the nominal power of the system (in this case the power supply). $\Delta \mathrm{P}$ is the power, which would be drawn from the grid by the power supply. If this value is positive, the inverter feeds in additional power, and thus "delivers" control power to the grid.

$T_{a}$ is an inertia time constant, as commonly defined [14] [15] and toughed in lectures [16] [6]. It should be noted that some authors use a different definition (e.g. [11]) with a constant they name " $\mathrm{H}$ ", where $T_{a}=2 \cdot H$. In [14] a value of $T_{a}=10 \mathrm{~s}$ is used for the ENTSO-E grid. Further private communications consider $\mathrm{Ta}=6 \mathrm{~s} \ldots 14 \mathrm{~s}$. In [15] $T_{a}=24 \mathrm{~s}$ is derived from a grid failure of the ENTSO-E grid ("Emslandvorfall", 4.11.2006). Since this value relates to the real behaviour of the ENTSO-E grid and because a larger value of $T_{a}$ gives the worst case for the considerations in this paper, this value of $T_{a}=24 \mathrm{~s}$ is selected for further considerations in this publication.

Fig. 7 shows the measured frequency (orange) for one hour on 14.Aug. 2015. The data is measured by a team at the author's university and is available on the author's website [17]. Assuming an inertia time constant $T_{a}=24 \mathrm{~s}$, the required power demand $\Delta P$ (blue) can be calculated from the time derivation of the frequency slope according to equation (3). The frequency is filtered with a running average using 3 averaged values to achieve reasonable results (red, overlaying with the unfiltered curve).

It is obvious that the required control power is only a very fraction in the range of less than $+/-0.15 \%$ of the rated power of the power supply. This shows that the hardware must not be changed, but is certainly able to provide the required control power during daily operation.

Usually, elcap sizes are selected by two criteria: Voltage ripple mitigation and lifetime due to current ripple and ESR (equivalent series resistor). The current variation is well approximately proportional to the power variation. However, compared to the typical current ripple in an elcap, which needs to provide the full power (related to $100 \%$ of the power) during zero crossings of the voltage, this amplitude of the current variations is more than an order of magnitude lower. In addition, the frequency of a less than a Hertz leads to the conclusion, that there is negligible additional impact on the elcap's lifetime.

The voltage fluctuation on the intermediate voltage storage elcap can be calculated as follows:

Generally, the voltage change $\Delta U_{C}(t)$ on a capacitor $C$ is calculated from the integral of the charging current $\Delta I(t)$ :

$$
{ }_{\Delta} U_{C}(t)=\frac{1}{C} \cdot \int \Delta I(t) d t
$$

This charging current $\Delta I(t)$ results from the control power $\Delta P(t)$. Assuming a fairly constant capacitor voltage of $U_{0}$ (which is the intermediate voltage), it is:

$$
\Delta P(t)=U_{0} \cdot \Delta I(t)
$$

Combining the two equations results in:

$$
{ }_{\Delta U} C^{(t)}=\frac{1}{C} \cdot \int \frac{\Delta P(t)}{U_{0}} d t
$$


If equation (3) is inserted, the integral cancels with the time derivative. Expressing the capacity $C$ by its nominal energy content $E_{0}$ results in:

$$
\frac{\Delta U_{C}(t)}{U_{0}}=T_{a} \cdot \frac{1}{2} \cdot \frac{P_{0}}{E_{0}} \cdot \frac{\Delta f}{f_{0}}
$$

This equation is used to calculate the voltage fluctuations on the intermediate voltage capacitor.

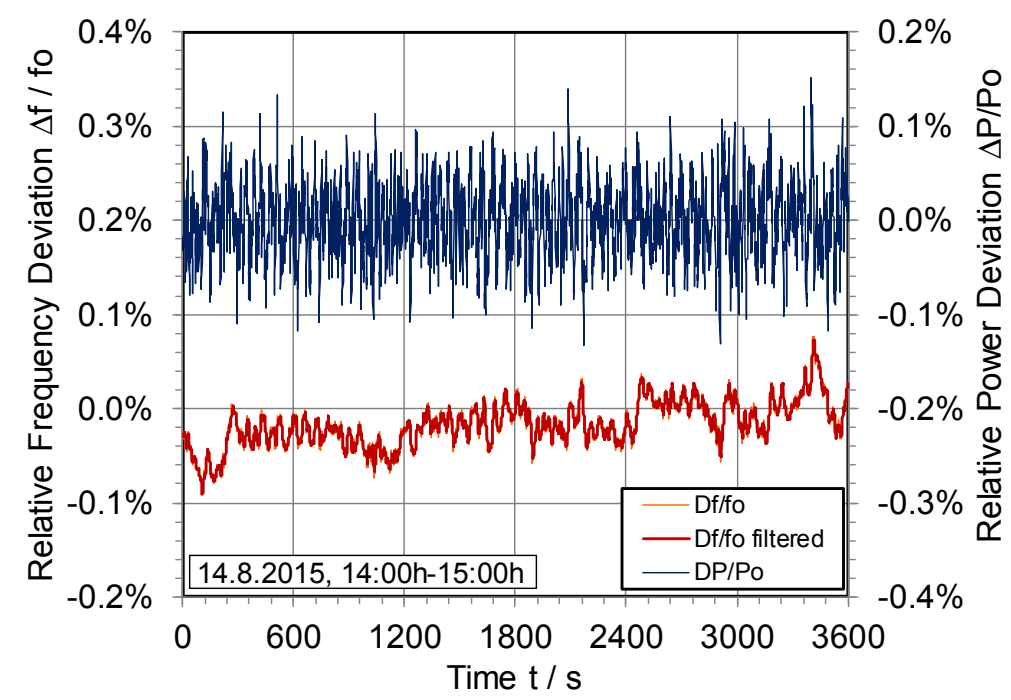

Fig. 7: Measured frequency for one hour and related calculated control power $\Delta \mathrm{P} / \mathrm{P}_{0}$ with an inertia time constant $T_{a}=24 \mathrm{~s}$.
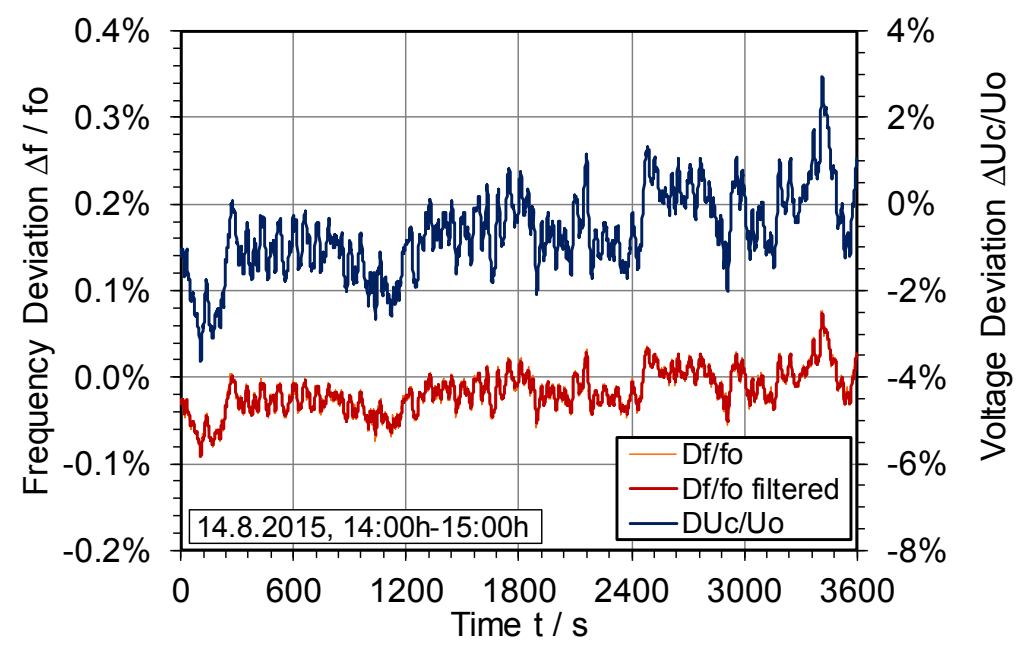

Fig. 8: Measured frequency for one hour and related calculated voltage fluctuation on a capacitor with an energy content of $300 \mathrm{~J}$.

The required power is used to charge and de-charge a capacitor with typical maximum energy content of $E_{0}=300 \mathrm{~J}$, which relates to charging directly the DC-link capacitor (see above). From this the capacitor voltage and its fluctuation can be calculated. The calculated results are shown for one hour on 14. Aug. 2015 Fig. 8 (blue curve).

The voltage variation during the investigated time remains between $+/-3.6 \%$ of the nominal voltage. This is a quite small value, which can be handled easily by power electronics. This shows that typical intermediate voltage elcaps can be used and no additional hardware is required to implement virtual inertia control in power supplies. 


\section{Control concept}

Typically, the DC to AC stage of a PV inverter is controlled by the intermediate capacitor voltage as e.g. described in [18] and illustrated in Fig. 9. The part in the yellow dashed rectangle is the typical control circuit for the DC to AC stage. If the intermediate capacitor voltage increases, there is too much power delivered by the PV panel and the inverter increases the current, and thus the power to the grid. If the intermediate voltage is too low, the inverter reduces the power. In general, the controller aims to keep the intermediate voltage constant at a given reference value. There are a number issues associated with this control, but those details are not important for this particular approach.

The general idea is to hook up this existing control circuit with the virtual inertia control (red part). As derived in equation (7) the variation of the intermediate capacitor voltage should be proportional to the grid frequency variation. Therefore, the reference value for the intermediate voltage control gets an offset which is proportional to the grid frequency deviation provided by the $\mathrm{f}$ to $\mathrm{V}$ converter. If the grid frequency increases, the set value for the intermediate frequency is increased proportionally. Then, the controller sets the power such that the intermediate voltage follows the set value. According to equation (6) this leads inherently to the required dependence of the power on the derivative of the grid frequency as required for virtual inertia control (compare equation (3) ). In addition, this kind of control makes sure that the intermediate voltage remains within necessary limits, because also the grid frequency must remain between given limits.

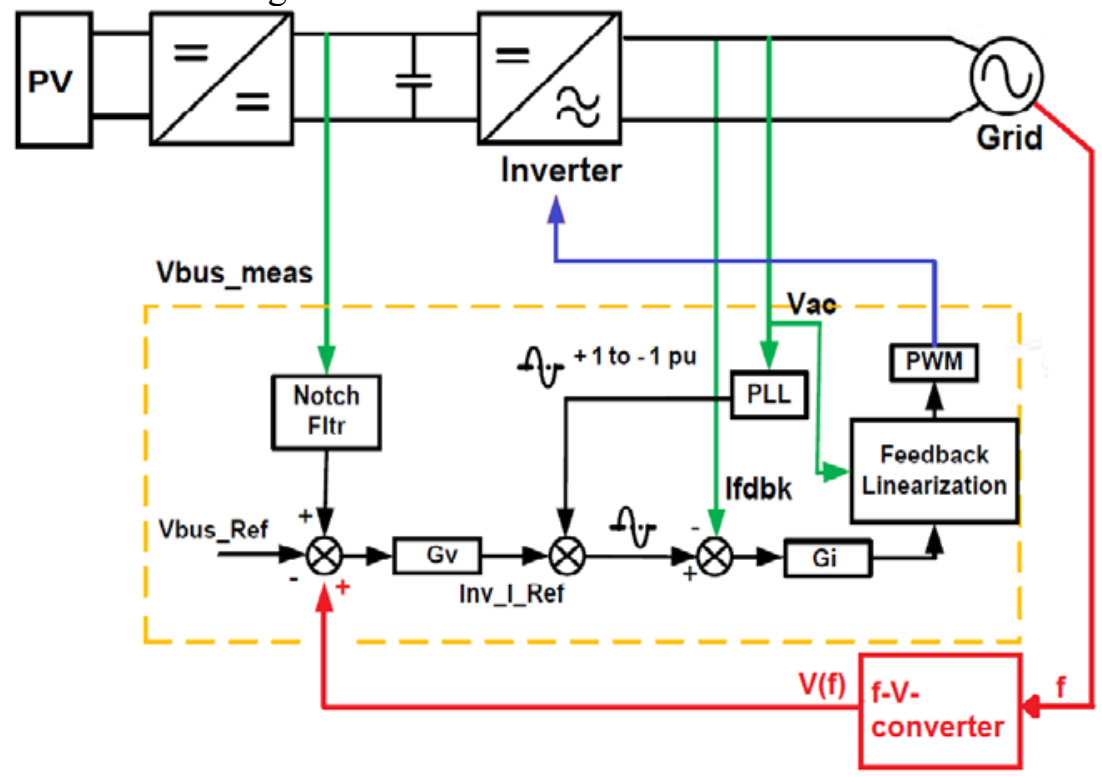

Fig. 9: General control concept. Based on a figure from [18].

\section{Measurements}

The same control behaviour is used in the rectifier and power factor correction (PFC) stage of a switched mode power supply. Here, also the grid current and thus the power is controlled according to the intermediate voltage (see e.g. [19]). To prove the control concept of the virtual inertia, a PFC circuit is used and modified, because its hardware and especially its documentation was available. Details are described in [20]. The heart of the $46 \mathrm{~W}$ PFC consist of a controller chip TDA4863 by Infineon [21]. Fig. 10 shows the related part of the circuit diagram. Pin 1 of the chip is the input sensing the intermediate voltage, which is set down by the voltage divider consisting of R5 to R8 and R9 9 R10. Here, an additional signal, which offsets the sensed intermediate voltage, is added by resistor $\mathrm{R} 21$. This voltage offset must be inversely proportional to the grid frequency deviation. If the intermediate voltage should increase, the sensed voltage must be lower such that it appears "correct" with increased intermediate voltage.

As a proof, a voltage signal representing a frequency deviation is applied to this point. Fig. 11 shows the measurement with a linearly increasing and decreasing signal (red) representing a linear decay and increase of the grid frequency. The orange curve shows the measurement of the intermediate voltage. It clearly follows the inverted control signal. The input power is shown in blue. It oscillates with $100 \mathrm{~Hz}$. 
The dark blue curve shows the ideally expected power slope, which should be a square wave signal. The amplitudes of the voltage and power variations are exaggerated in this circuit compared to an operation in "real life" in order to demonstrate the functionality. The measurement shows that indeed the input power nearly follows the square wave function. This proves that the controller indeed behaves like needed according to equation (3) and provides the required function for the virtual inertia.

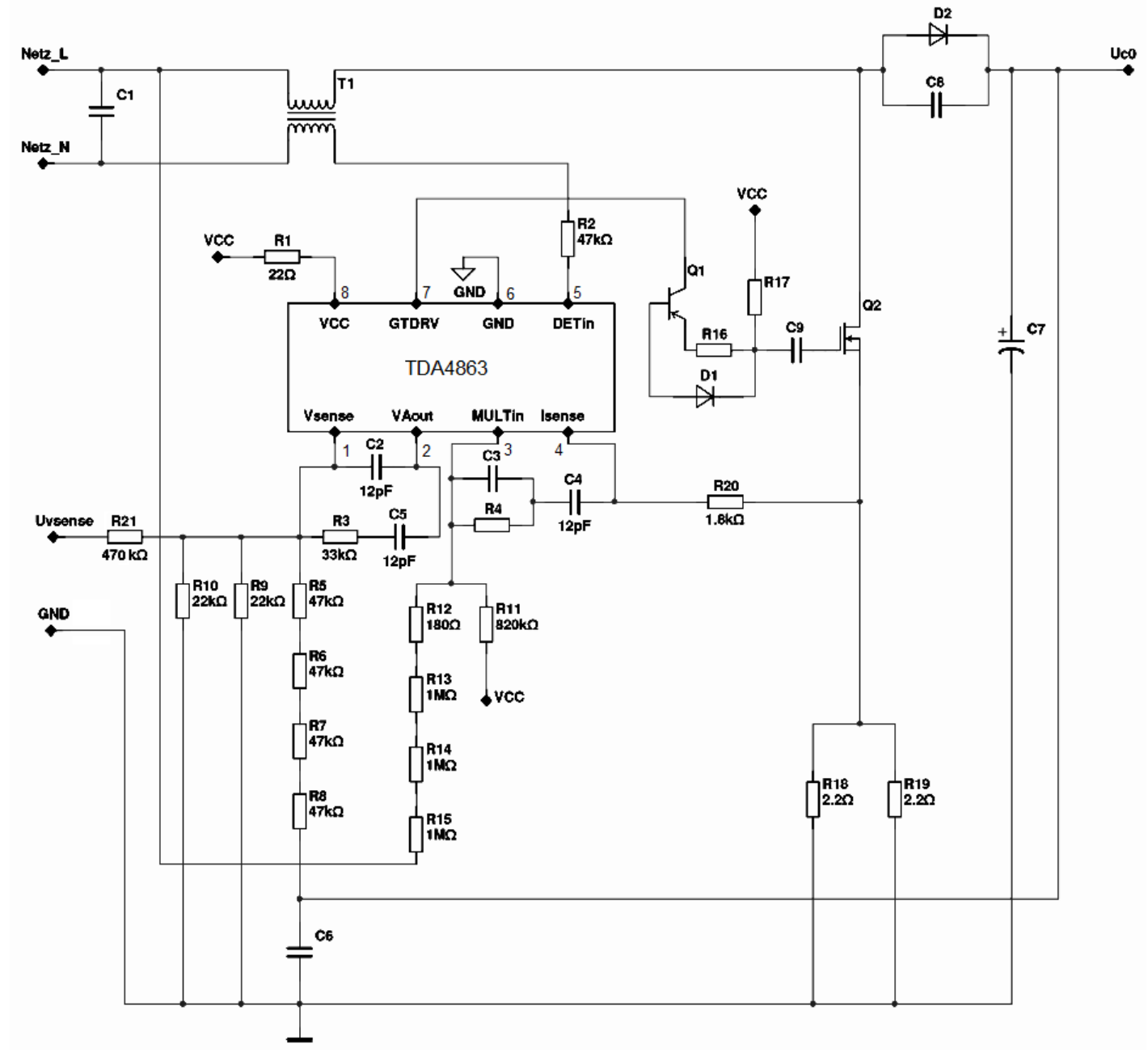

Fig. 10: Circuit diagram of the modified PFC controller [21].

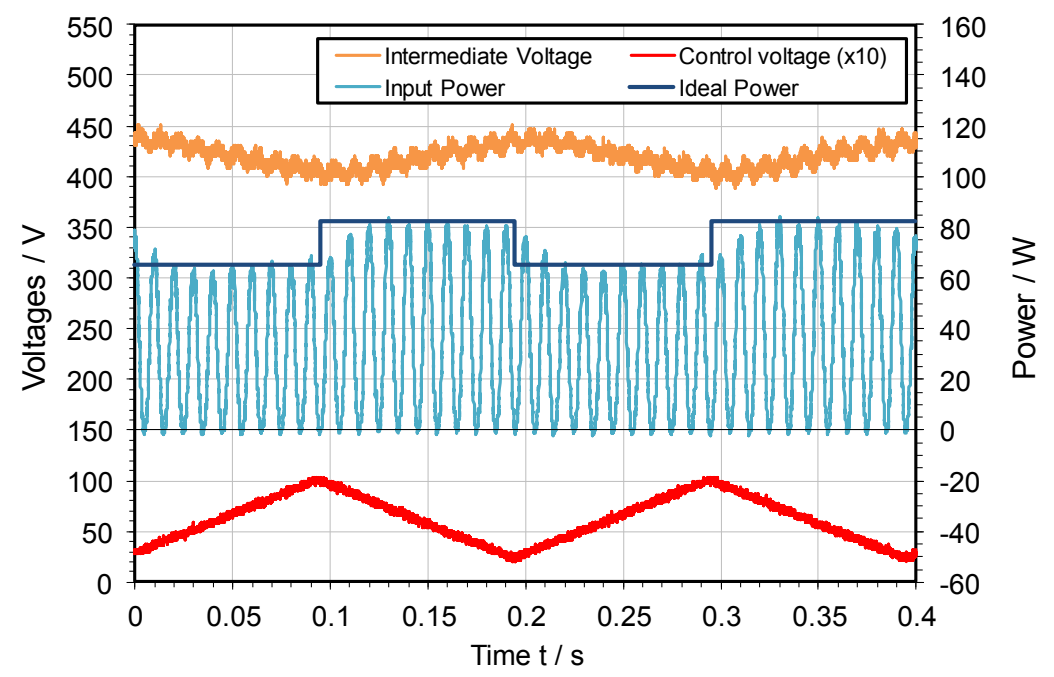

Fig. 11: Measurements of the intermediate voltage (orange) and input power (blue) with a linearly increasing and decreasing control signal (red) representing a grid frequency deviation. 


\section{Conclusions}

Instantaneous power control of the power grid with electronic converters becomes necessary soon in Germany and Europe. It is shown that this requires additional power about $5 \mathrm{~W}$ with an energy of $50 \mathrm{~J}$ per event for each installed kWpk. This can easily be implemented in PV converters. The required storage size is in the order of magnitude as DC ripple cancellation capacitors in single phase converters. This means that existing hardware can be used and no significant additional storages like e.g. super capacitors or small batteries are needed for those inverters, which use intermediate voltage capacitors. It is shown that during daily operation the additional power ripple (and thus current ripple) is in the order of $0.1 \%$ and an influence on the lifetime of the capacitors can be neglected. The voltage ripple of the intermediate voltage will typically remain between $+/-3.6 \%$ of the nominal voltage and is thus easily covered by existing hardware. The related control can be easily extended by adding a voltage signal to the control voltage, which is proportional to the frequency deviation. Then, the existing controller inherently sets the required additional power fluctuation required for the virtual inertia function. Concluding, no cost for additional hardware appear and only the control needs to be adapted.

\section{References}

[1] Johannes Weniger, Tjarko Tjaden, Volker Quaschning, ,Sizing and grid integration of residential PV battery systems", proceedings of the 8th International Renewable Energy Storage Conference and Exhibition (IRES 2013), Berlin, Germany, 18.-20. Nov. 2013.

[2] Eberhard Waffenschmidt, "Dimensioning of decentralized photovoltaic storages with limited feed-in power and their impact on the distribution grid", Energy Procedia (2014), 31.Jan. 2014, pp. 88-97.

[3] Agora Energiewende, „Agorameter“, available online (12.June 2016), https://www.agora-energiewende.de/de/themen/-agothem-/Produkt/produkt/76/Agorameter/

[4] Bodo Giesler, Bruno Burger, "Erneuerbare Energien konkurrieren zunehmend mit Grundlastkraftwerken“, Proceedings of the 2. Otti-Konferenz „zukünftige Stromnetze für Erneuerbare Energien“, 27.-28.Jan. 2015, p. 52-57.

[5] A.-C. Agricola, H. Seidl, S. Mischinger, C. Rehtanz,, M. Greve, U. Häger, D. Hilbrich, S. Kippelt, A. Kubis, V. Liebenau, T. Noll, S. Rüberg, T. Schlüter, J. Schwippe, C. Spieker, J. Teuwsen, „dena-Studie Systemdienstleistungen 2030 - Sicherheit und Zuverlässigkeit einer Stromversorgung mit hohem Anteil erneuerbarer Energien", Deutsche Energie-Agentur GmbH (dena), Energiesysteme und Energiedienstleistungen, Berlin, Germany, Feb. 2014.

[6] Albert Moser, "Elektrische Energieversorgungssysteme - Technische und wirtschaftliche Zusammenhänge", Skript zur Vorlesung "Elektrische Anlagen II", RWTH Aachen, Institut für Elektrische Anlagen und Energiewirtschaft, Forschungsgesellschaft Energie an der RWTH Aachen, 1. Auflage 2010, p. 342.

[7] Yong Chen, Ralf Hesse, Dirk Turschner, Hans-Peter Beck, "Improving the grid power quality using virtual synchronous machines", Proceedings of the International Conference on Power Engineering, Energy and Electrical Drives (POWERENG 2011), 11.-13. May 2011, Malaga.

[8] Visscher, K.; de Haan, S.W.H.; Virtual synchronous machines for frequency stabilisation in future grids with a significant share of decentralised generation, Proceedings of the CIRED SmartGrids conference; June 2008; Germany

[9] Pedro Rodriguez, "Control of Grid-Interactive Power Converters: The Synchronous Power Controller", Presentation at ECPE-Workshop "Power Electronics in the Electrical Network", Kassel, Germany, 12. March 2013.

[10] Jonathan Brisebois, Noël Aubut, "Wind Farm Inertia Emulation to Fulfill Hydro-Québec's Specific Need", Proceedings of the IEEE PES General Meeting - 978-1-4577-1002-5/11 Summer 2011, July 24-28 2011. Detroit, Michigan, USA

[11] F. Gonzalez-Longatt, E. Chikuni, W. Stemmet, K. Folly, "Effects of the Synthetic Inertia from Wind Power on the Total System Inertia after a Frequency Disturbance", IEEE PES PowerAfrica 2012 Conference and Exposition, Johannesburg, South Africa, 9.-13.July 2012.

[12] "ENTSO-E Network Code for Requirements for Grid Connection Applicable to all Generators", ENTSO-E, 8 March 2013.

[13] Conrad-Elektronik, Electrolytic Capacitors, Internet 6.7.2014: http://www.conrad.de/ce/de/overview/0245812/Elektrolyt-Kondensatoren 
[14] Martin Boxleitner, Günther Brauner, "Virtuelle Schwungmasse", 6. Internationale Energiewirtschaftstagung an der TU Wien (IEWT 2009), Wien, 2009.

[15] Philipp Strauß, "Einfluss des Frequenzverhaltens kleiner Generatoren und Lasten auf Stromnetze unter besonderer Berücksichtigung großer Netzstörungen", Dissertation (PhD Thesis) Universität Kassel, Technologoy \& Science Publishers, Kassel, Germany, 2009, ISBN 978-3-00-029475-4

[16] B.R.Oswald, „Netzregelung“, Skript zur Vorlesung „Elektrische Energieversorgung 2“, korrigierte Fassung, Universität Hannover, Hannover, Germany, 2005.

[17] E. Waffenschmidt, „An der TH-Köln gemessene Netzfrequenz-Daten“, available online (12.June 2016), http://www.100pro-erneuerbare.com/netze/messdaten/messdaten.htm\#netzfrequenz

[18] "Digitally Controlled Solar Micro Inverter using C2000 Piccolo Microcontroller", CCS User Guide Version 1.0, 24 April 2014, TMS320C2000TM Systems 2 Applications Collateral, Texas Instruments 2014.

[19] Miroslaw Mrozek, "Power Factor Correction Algorithm in AC-DC Converter", Problemy Eksploatacji Maintenance Problems, 2-2013, p.129

[20] Nora Kovacs, "Momentanregelung mit Licht emittierden Dioden (LED) Lampentreibern", Master Thesis at TH-Köln, 23. May 2016.

[21] "Boost Controller TDA4863 - Popwer Factor Controller IC for High Power Factor and Low THD", Infineon, Datasheet, Rev. 2, Feb. 2005. 